\title{
Failure mode and dynamic response of a double-sided slope with high water content of soil
}

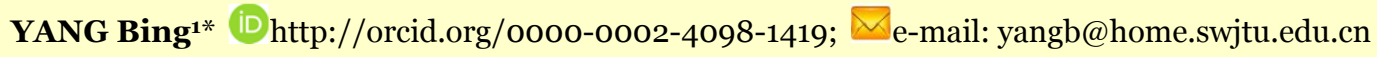 \\ GAO Fu-ping2 iD http://orcid.org/oooo-0oo2-0287-9763; e-mail: fpgao@imech.ac.cn \\ JENG Dong-sheng1,3 iDhttp://orcid.org/oooo-0003-0199-0918; e-mail: d.jeng@griffith.edu.au \\ * Corresponding author \\ 1 School of Civil Engineering, Southwest Jiaotong University, Chengdu 610031, China \\ 2 Institute of Mechanics, Chinese Academy of Sciences, Beijing 10o19o, China \\ 3 School of Engineering and Built Environment, Griffith University Gold Coast Campus, QLD 4222, Australia
}

Citation: Yang B, Gao FP, Jeng DS (2018) Failure mode and dynamic response of a double-sided slope with high water content of soil. Journal of Mountain Science 15(4). https://doi.org/10.1007/s11629-017-4616-4

(C) Science Press, Institute of Mountain Hazards and Environment, CAS and Springer-Verlag GmbH Germany, part of Springer Nature 2018

\begin{abstract}
A double-sided slope with high water content in sandy clay was considered under the action of seismic load. Its failure mode and dynamic response were investigated using a hydraulic servo shaking table test. The typical characteristic of failure mode and dynamic responses of the double-sided slope were analyzed. Experimental results show that slope failure undergoes a process of progressive deformation. The slope failure mode can be explained as creep sliding landslide. AFA (Amplification Factor of Acceleration) at the surface and inner parts of the slope shows an increasing trend with the increase of relative elevation. The relationship between AFA and EAA (Excitation Amplitude of Acceleration) is nonlinear. An empirical formula is proposed to describe preferably the relationship between AFA, relative elevation and dimensionless EAA. The AFA at the middle and upper parts of the slope increases apparently with increasing EFA (Excitation Frequency of Acceleration).
\end{abstract}

Keywords: Slope displacement; Slope failure mode; Soil water content; Shaking table test; Landslides

Received: 29 July 2017

Revised: 8 December 2017

Accepted: 25 January 2018

\section{Introduction}

Landslides induced by earthquake are one of the most common geological hazards in mountainous regions (Huang and $\mathrm{Li}$ 2009a,b; Wasowski et al. 2011). Thousands of geological disasters have been triggered by the Wenchuan earthquake $\left(M_{S}=8.0\right)$ in Western Sichuan, China, most of which (more than 60,000) are landslides (Huang and Li 2009a). There exist tens of large scale landslides ( $>$ ten million $\mathrm{m}^{3}$ ) and the number of landslides with area larger than $50,000 \mathrm{~m}^{2}$ is more than one hundred (Huang and Li 2009a). The landslides can lead to extensive damage to human lives and structures (e.g. Daguangbao landslides, Wangjiayan landslides triggered by the Wenchuan Earthquake). The failure mode and dynamic response of the slope under the action of earthquake load have placed an important role in the study of landslides, which are able to provide scientific guideline of earthquake resistant design. This problem attracted great attentions among researchers (e.g. Arango and Seed 1974; Yang et al. 2002; Ling et al. 2005; Lin and Wang 2006; Latha and Garaga 2010; Huang et al. 2011; Huang et al. 
2012; Wang and Lin 2011; Liu et al. 2013; Fan et al. 2016).

Arango and Seed (1974) investigated the seismic stability of clay slopes and found that strong shaking resulted in development of a distinct "yield acceleration" that marked initiation of permanent deformation in their embankments. Varnes $(1954,1978)$ devised the most widely used system of landslide classification, in which some failure modes of slope are involved. Cruden and Varnes (1996) proposed separate names for the movement mode during each stage of a given landslide. Huang (2009) and Huang et al. (2011) gathered a large body of survey data about the landslides triggered by 5.12 Wenchuan Earthquake, and concluded several failure modes of slopes triggered by seismic load, i.e. shattering-cracking, shattering-sliding, shattering-falls and ejection. Hungr et al. (2014) updated the Varnes classification of landslide types, and modified the definition of landslide-forming materials.

Lin \& Wang (2006) used uniform medium sand(water content of $5.1 \%$ ) to investigate the dynamic response of model slope exposed to sine wave $(8.9 \mathrm{~Hz})$, and the results show that the response of the slope remains linear with a loading amplitude of up to $0.4 \mathrm{~g}$ and nonlinear response appears when the loading amplitude becomes larger than 0.5g. Xu et al. (2008) designed model slope consisting of gravelly soil (water content of 9\%), and studied the dynamic response of model slope under the action of El-Centro wave, Kobe wave and Tongmai man-made wave. Srilatha et al. (2013) conducted the shaking table tests about effect of frequency on seismic response of soil slope (clayey sand material), and found that the frequency of wave has some influences on the acceleration amplification factor.

Liu et al. (2013) investigated the response of high-strength rock slope subjected to seismic waves by shaking table test, and found that the amplification factor of peak horizontal acceleration (PHA) increases with the elevation of model slope, and the different increasing patterns exist at the upper and lower part of the slope. Liu et al. 2014) further studied the effect of lithology and slope structure on seismic response of steep slope. As reported in Liu et al. $(2013,2014)$, the amplification factor of peak horizontal acceleration in the lower half of each model slope is independent of the excitation intensity and fairly stable, and the sudden increase of amplification factor in the upper part of the slope indicates the drastic deterioration of inner structure of model slope. Recently, Fan et al. (2016) studied dynamic response of a weak intercalated rock slope parallel to geological bedding (bedding slopes) and counter-bedding slopes. They found that acceleration amplification factor of the slope increases gradually with the increasing relative elevation. Furthermore, the input earthquake intensity is greater than $0.3 \mathrm{~g}$, the bedding and counter-bedding slopes present nonlinear dynamic response.

The aforementioned studies provided researchers an insight into failure mode and dynamic response of slope, which mainly focused on the slope with low water content of rock and soil. However, most previous studies paid little attention to the failure mode and dynamic response of slope with high water content (e.g. the water content is between plastic limit and liquid limit). In fact, when the soil in the slope has high water content, its modulus of deformation, strength parameter, damping ratio will be different from those with low water content. The failure mode and dynamic response of slope with high water content will present new phenomena.

In this paper the failure mode and dynamic response of a double-sided slope with high water content in sandy clay subjected to seismic loadings will be investigated by shaking table tests. The physical process of slope failure will be analyzed, and the dynamic response of the slope will be discussed in detail.

\section{Experimental Details}

\subsection{Similarity analysis}

The main factors influencing the dynamic response of slope in seismic loading are shown in Table 1.

The peak acceleration $\left(a_{p}\right)$ induced by seismic loading at any point within the slope can be written as

$$
a_{p}=\varphi\left(H, \alpha, z, \gamma, c, \emptyset, E_{s}, v, w, g, a, f, t_{s}\right)
$$

According to $\pi$ theorem, the equation (1) above can be rewritten as 
Table 1 Main factors influencing the dynamic response of slope

\begin{tabular}{|c|c|c|}
\hline Variable & Symbol & Dimensions \\
\hline \multicolumn{3}{|l|}{ Related to slope body } \\
\hline Slope height & $H$ & $\mathrm{~L}$ \\
\hline Slope angle & $\alpha$ & 1 \\
\hline Elevation at measuring point & $z$ & $\mathrm{~L}$ \\
\hline Unit weight of soil & $\gamma$ & $\mathrm{ML}^{-2} \mathrm{~T}^{-2}$ \\
\hline Cohesion & $c$ & $\mathrm{ML}^{-1} \mathrm{~T}^{-2}$ \\
\hline Internal friction angle of soil & $\varnothing$ & 1 \\
\hline Modulus of compressibility & $E_{s}$ & $\mathrm{ML}^{-1} \mathrm{~T}^{-2}$ \\
\hline Poisson's ratio & $v$ & 1 \\
\hline Water content & $w$ & 1 \\
\hline Gravity acceleration & $g$ & $\mathrm{LT}^{-2}$ \\
\hline \multicolumn{3}{|l|}{ Related to seismic load } \\
\hline Peak acceleration of load & $a$ & $\mathrm{LT}^{-2}$ \\
\hline Principle vibration frequency & $f$ & $\mathrm{~T}^{-1}$ \\
\hline Time of duration & $t_{s}$ & $\mathrm{~T}$ \\
\hline
\end{tabular}

$\frac{a_{\mathrm{p}}}{a}=\varphi^{\prime}\left(\frac{z}{H}, \alpha, \frac{c}{\gamma H}, \emptyset, \frac{E_{S}}{\gamma H}, \nu, w, \frac{a}{g}, f \sqrt{\frac{H}{g}}, t_{s} f\right)$

in which $a_{p} / a$ is the ratio of the earthquakeinduced peak acceleration and peak acceleration of seismic loading, i.e. amplification factor of acceleration; $\mathrm{z} / \mathrm{H}$ is the relative elevation, which indicates the location of the measuring point at the slope; $\frac{c}{\gamma H}$ represents the ratio of cohesion of soil and self-weight stress of soil, which is called stability number by Taylor (1937); $\frac{E_{s}}{\gamma H}$ represents the ratio of compression modulus of soil and selfweight stress of soil, which is related to the deformation of soil; a/g represents the ratio of peak acceleration of seismic load and gravitational acceleration; $f \sqrt{\frac{H}{g}}$ represents the ratio of the frequency of seismic load and natural frequency of slope, which is called frequency parameter.

Based on theorem of dimensional analysis, the following dimensionless parameters are introduced,

$$
\frac{z}{H}, \alpha, \frac{c}{\gamma H}, \emptyset, \frac{E_{S}}{\gamma H}, v, w, \frac{a}{g}, f \sqrt{\frac{H}{g}}, t_{s} f
$$

In order to simulate the behavior of prototype truly with model tests, the values of similarity rules must be equal between model and prototype. However, it is difficult to keep the same values of similarity rules between model and prototype for all parameters in model tests. In many cases, the similarity of main parameters are ensured, but ignoring the similarity of minor factors. Based on this principle, the experiments have been designed.

In this paper, the relationship between $a_{p} / a$ and $z / H, a / g, f \sqrt{\frac{H}{g}}$ will be investigated.

\subsection{Experimental apparatus}

A hydraulic servo shaking table with a loading platform of $3 \mathrm{~m} \times 2 \mathrm{~m}$ is employed to conduct the tests, which can provide seismic or any other vibration conditions (single degree of freedom). The shaking table with the displacement amplitude of $100 \mathrm{~mm}$ has the payload of 2ot, which is able to output the acceleration within the range of $0.05 \mathrm{~g}$ $1.5 \mathrm{~g}$ and frequency range of $0.5-100 \mathrm{~Hz}$. A rigid box was designed and manufactured by us to prepare the model of slope, and the box has a length of $2 \mathrm{~m}$, width of $0.8 \mathrm{~m}$ and depth of $1.5 \mathrm{~m}$. One side wall of the box is made up of glass to observe the process of slope failure easily.

\subsection{Experimental Model}

The soil with a sand content of $50 \%$ is used in the experiment, which is classified as sandy clay according to the Chinese soil classification system. The model slope with water content of $17.1 \%$ is designed. The detailed properties of soil are listed in Table 2. The liquid index of sandy clay can be obtained from Table 2, i.e. $I_{L}=0.48$, which indicates that the soil is at the plastic state. The optimal water content of soil is $11 \%$, and the maximal dry density is $2.09 \mathrm{~g} / \mathrm{cm}^{3}$.

A double-sided slope is designed in the test. The model slope is constructed with a method of layer construction. The height of every layer is 10 $\mathrm{cm}$. During constructing the slope, the soil is rolled and compacted with a constant external force to keep the same porosity within the slope. When the model slope is constructed well, the compactness of sandy clay is tested, i.e. $86.4 \%$, which indicates that the sandy clay in the slope is medium dense. The white sand with a vertical banding distribution is placed along the inner side of glass wall, so that the deformation of the soil can be observed in the test.

Table 2 Physical parameter of sandy clay

\begin{tabular}{|l|l|l|l|l|l|l|}
$\begin{array}{l}\text { Water content, } \\
w(\%)\end{array}$ & $\begin{array}{l}\text { Density, } \rho \\
\left(\mathrm{g} / \mathrm{cm}^{3}\right)\end{array}$ & $\begin{array}{l}\text { Cohesion, } \\
c(\mathrm{kPa})\end{array}$ & $\begin{array}{l}\text { Internal friction } \\
\text { angle } \varnothing\left(^{\circ}\right)\end{array}$ & $\begin{array}{l}\text { Compression } \\
\text { modulus, } E_{s}(\mathrm{MPa})\end{array}$ & $\begin{array}{l}\text { Plastic limit, } \\
w_{p}(\%)\end{array}$ & $\begin{array}{l}\text { Liquid limit, } \\
w_{l}(\%)\end{array}$ \\
\hline 17.1 & 2.114 & 20.3 & 15 & 5.08 & 9 & 26
\end{tabular}




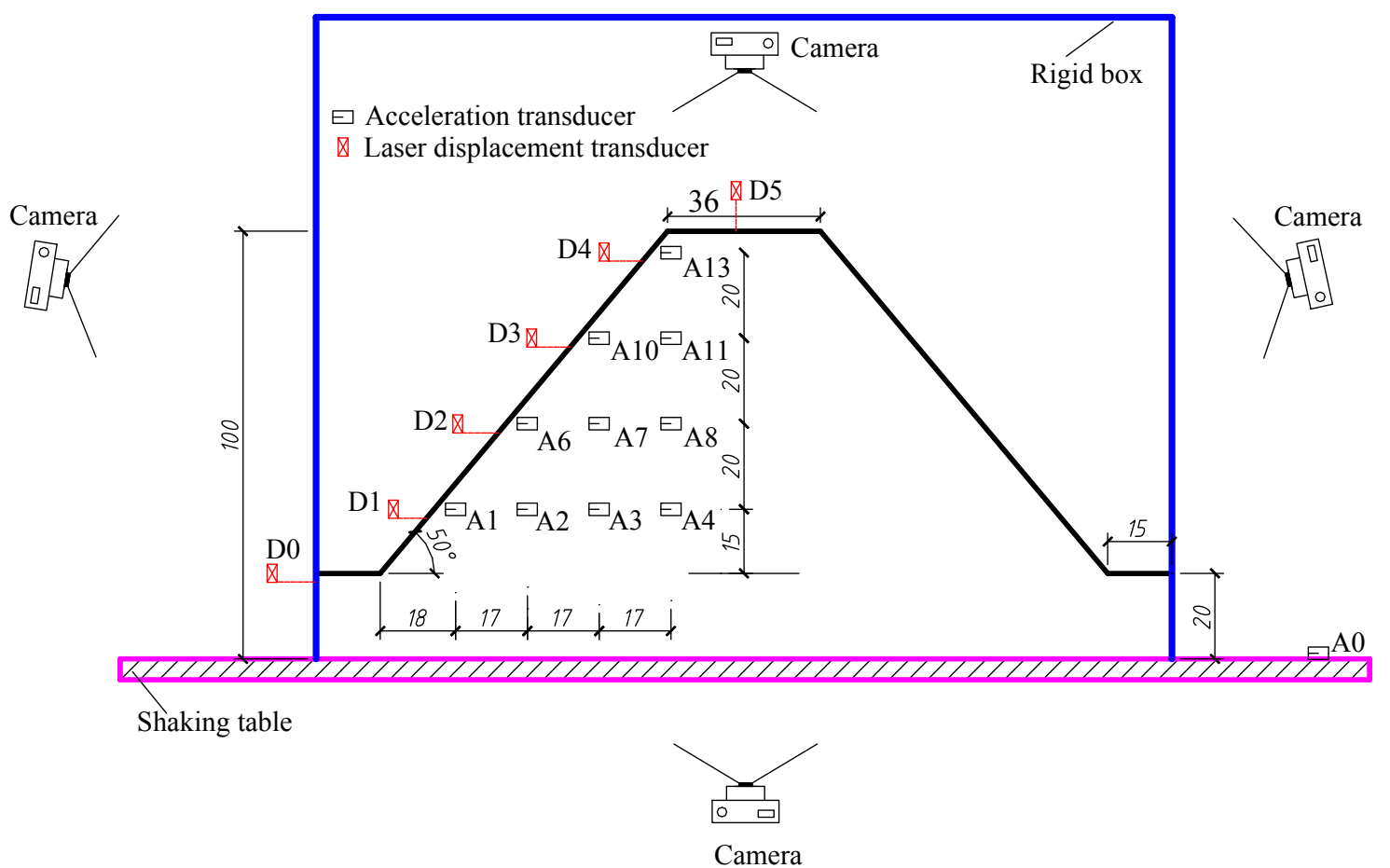

Figure 1 Schematic diagram of model slope (unit: $\mathrm{cm}$ ).

Table 3 Values of similarity rules in model test

\begin{tabular}{|l|c|c|c|c|c|c|c|c|c|c|} 
Parameter & $\frac{c}{\gamma H}$ & $\frac{E_{s}}{\gamma H}$ & $f \sqrt{\frac{H}{g}}$ & $\emptyset$ & $\alpha$ & $z / H$ & $v$ & $\frac{a}{g}$ & $t_{s} f$ \\
\hline Value & 1.22 & 300.38 & $\begin{array}{l}0.29,0.57,0.85 \\
1.14,1.42,1.71\end{array}$ & $15^{\circ}$ & $50^{\circ}$ & $\begin{array}{l}0.19,0.44, \\
0.69,0.94\end{array}$ & 0.28 & $\begin{array}{l}0.1,0.2,0.3, \\
0.4,0.5,0.6\end{array}$ & $\begin{array}{l}12,24,36, \\
48,60,72\end{array}$ \\
\hline
\end{tabular}

The height of model slope is $800 \mathrm{~mm}$, and the length of slope at the top is $360 \mathrm{~mm}$. The slope angle is $50^{\circ}$. The tested model slope is depicted in Figure 1, and the values of similarity rules shown in Eq. (3) are listed in Table 3.

\subsection{Instrumentation}

The laser displacement transducer (LDT) is used to measure the displacement at the surface of slope. The LDT with a measuring range of $100 \mathrm{~cm}$ and an accuracy of $1.0 \mathrm{~mm}$ is employed to measure the horizontal displacement at the location of slope surface and the settlement at the top of slope. Accelerometers have a sensitivity of $202 \mathrm{mv} / \mathrm{g}$, and are buried within the slope to measure the acceleration. Four cameras are used to record the physical process during the course of test. The detailed layout is shown in Figure 1. There are eleven accelerometers used in the test, in which $\mathrm{A}_{0}$ is placed at the shaking table to monitor the input signal. The LDT $\left(D_{0}\right)$ is used to measure the displacement of rigid box to monitor the input of displacement. The slope surface at the left is the main measuring location and Four LDTs are installed at this surface. The high-speed data acquisition device with a type of USB-6255 produced by National Instruments in USA is employed to obtain the measurement data.

\subsection{Test program}

Since a sine wave has the advantage of single frequency and uniform amplitude, which can exclude the disturbance of other factors, it is adopted to simulate the excitation of seismic wave. The typical sine wave with a frequency of $3 \mathrm{~Hz}$ for input is shown in Figure 2. All the input waves have the duration of $12 \mathrm{~s}$, and the amplitudes of loading waves from $0.1 \mathrm{~g}$ to the critical values at which the 
slope will be in failure at an interval of $0.1 \mathrm{~g}$. In order to investigate the influence of loading frequency on the dynamic response, the loading frequency is changed from $1 \mathrm{~Hz}$ to $6 \mathrm{~Hz}$ at amplitude of $0.1 \mathrm{~g}$. Beyond those, other input waves have a fixed loading frequency with a value of $3 \mathrm{~Hz}$. Before every test the White Noise wave with a flat Fourier spectrum in all frequencies and amplitude of $0.03 \mathrm{~g}$ is used to excite the slope so as to investigate the variation of dynamic characteristics of slope. The detailed test loading sequence is shown in Table 4.

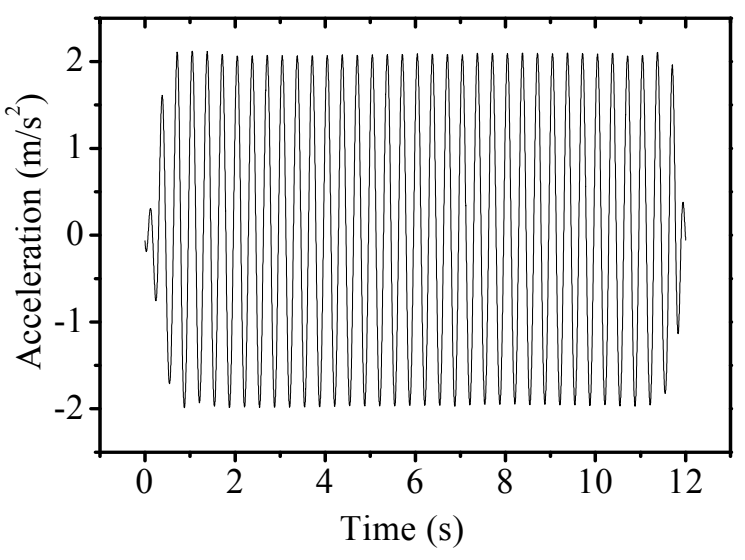

Figure 2 Typical sine wave of time history for input.

Table 4 Loading sequence of sine wave in model test

\begin{tabular}{|l|l|l|l|}
\hline Number & Load & Amplitude $(\mathrm{g})$ & Frequency $(\mathrm{Hz})$ \\
\hline $\mathbf{1}$ & White noise & $\mathbf{0 . 0 3}$ & - \\
\hline 2 & Sine wave & 0.1 & $1,2,3,4,5,6$ \\
\hline 3 & White noise & 0.03 & - \\
\hline 4 & Sine wave & 0.2 & 3 \\
\hline 5 & White noise & 0.03 & - \\
\hline 6 & Sine wave & 0.3 & 3 \\
\hline 7 & White noise & 0.03 & - \\
\hline 8 & Sine wave & 0.4 & 3 \\
\hline 1 & White noise & 0.03 & - \\
\hline 10 & Sine wave & 0.5 & 3 \\
\hline 12 & White noise & 0.03 & - \\
\hline
\end{tabular}

\section{Results and Discussions}

\subsection{Deformation process of slope during the action of dynamic load}

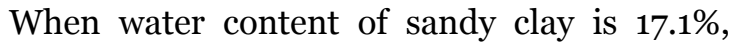
which indicates sandy clay is at the plastic state, the deformation process of slope is shown in Figure 3. According to the observation of physical process, when the amplitude of excitation acceleration (AEA) is no more than $0.3 \mathrm{~g}$, the slope is almost intact (see Figure 3a). When the AEA reaches to $0.4 \mathrm{~g}$, the slope has recognizable deformation (see Figure $3 b$ ). As shown in Figure 3, a small amount of settlements occur at the top of slope and a slight deformation appears at two sides of slope. With the increase of AEA, the deformation of the slope continues to develop. At $0.5 \mathrm{~g}$, there is the apparent deformation of the slope, as illustrated in Figure $3 \mathrm{c}$. The larger settlement at the top of the slope can be found easily from the figure and the convex deformation at two sides of the slope is clear at this instant. When the excitation acceleration reaches to $0.6 \mathrm{~g}$, the slope fails. There are considerable settlements at the top of the slope, and large deformation also occurs at left and right side of slope (see Figure 3d). The above analysis indicates that the sandy clay in the slope is not broken into pieces under the action of sine wave loading, when the slope is in failure. The failure of slope undergoes a progressive process of deformation, different from the quick failure mode shown in slopes with low water content (Xu et al. 2008). The failure mode of the slope tested in this paper can be explained as creep sliding landslide. It is inferred from above statements that it provides more time for residents to get away from the hazard sports when this type of slope is in failure.

The failure mechanism of the slope with high water content of sandy clay may be explained tentatively in the following statements. According to existing studies (Vanapalli et al. 1996), the cohesion of soil with higher water content is smaller. Xie et al. (2017) studied the influence of water content of soil on shear modulus of compacted soil and found that the shear modulus of soil decreases with increasing of water content. According to the results about dynamic parameters of soil (e.g. Hardin and Drnevich 1972; Das1993), the dynamic shear modulus of soil will decrease and damping ratio of soil will increase, when the dynamic load increases. The results reported by Zhao et al. (2003) and Zhang et al. ( 2011) indicate that the damping ratio of soil increases with increasing water content of soil. In this paper the water content of soil is $17.1 \%$, and the cohesion of soil is $20.3 \mathrm{kPa}$. According to above statements, the damping ratio is larger and shear modulus is smaller at this value of water content. At this condition, the strength of soil is smaller but it is 
able to bear large plastic deformation. Due to the large damping ratio and low shear modulus, most input energy provided by a sine wave is dissipated by damping ratio and large deformation of soil. More energy is needed to reach failure status although the strength of soil in the slope is low. Therefore, the slope with water content of $17.1 \%$ is in failure at the larger amplitude of excitation acceleration, i.e. $0.6 \mathrm{~g}$.

\subsection{Displacement at surface of slope}

The displacement at surface of slope is related to the deformation of slope. Figure 4 illustrates the typical time history of the displacement at the surface of slope (taking the point D3 as an example here). It can be found from the figure that the equilibrium position of time history curve has a distinct deviation when the slope undergoes an
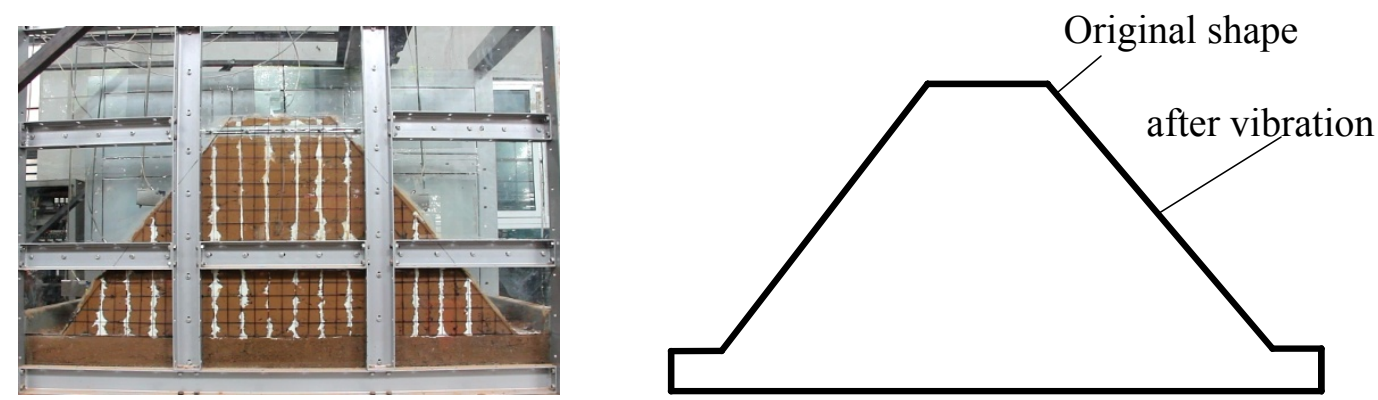

(a) Deformation mode at $0.1 \mathrm{~g}$
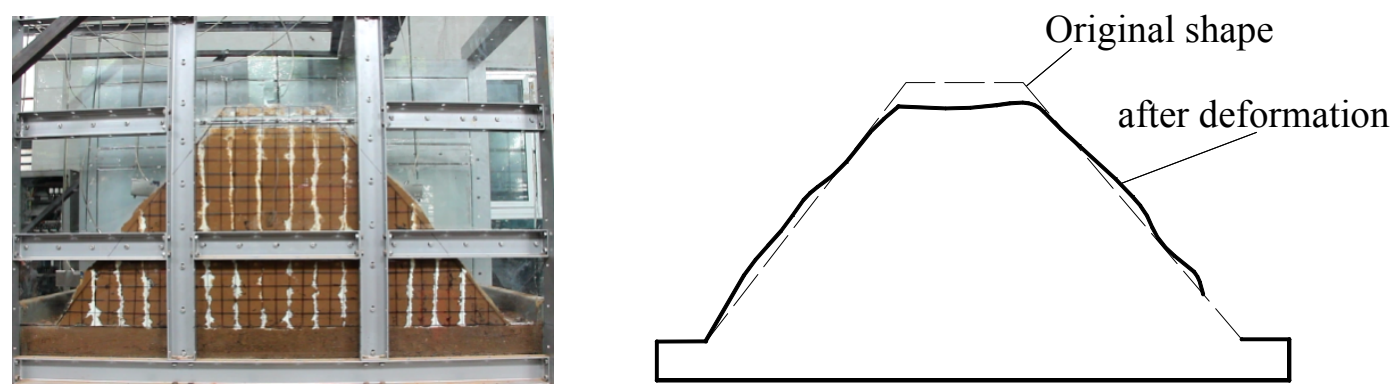

(b) Deformation mode at $0.4 \mathrm{~g}$
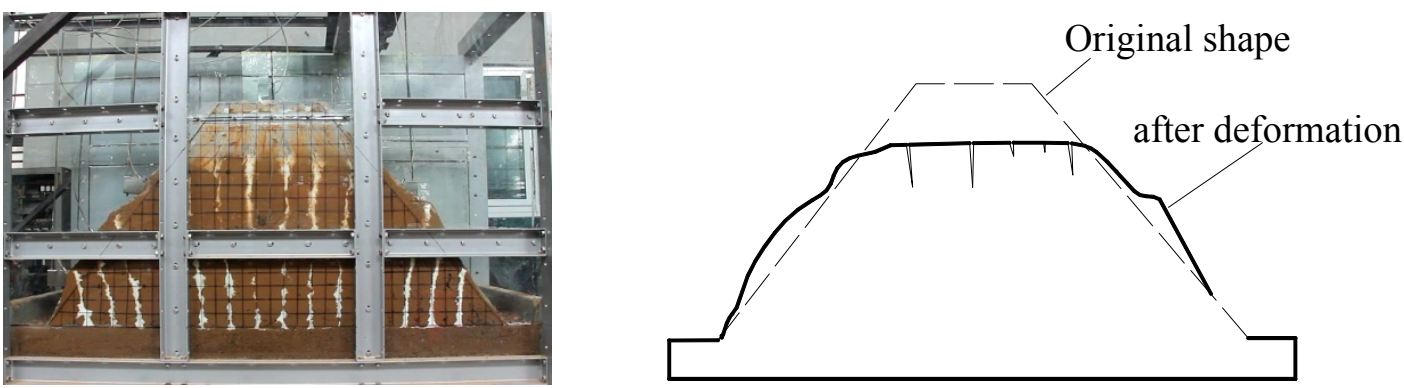

(c) Deformation mode at $0.5 \mathrm{~g}$
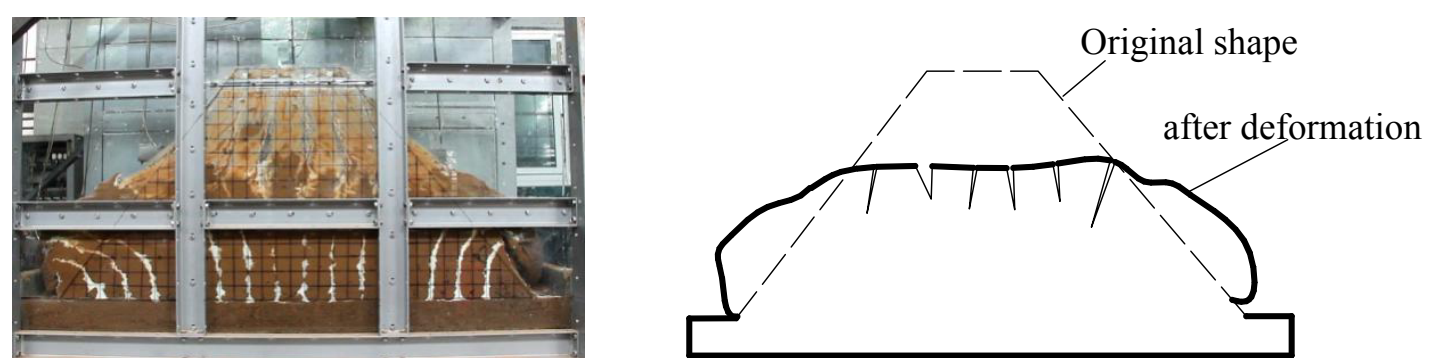

(d) Deformation mode at $0.6 \mathrm{~g}$

Figure 3 The deformation mode of the slope under sine wave load $(3 \mathrm{~Hz})$. 


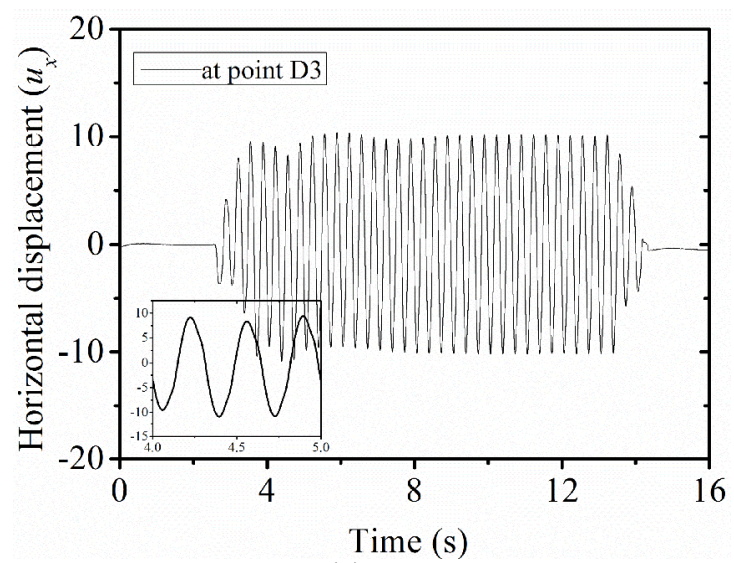

(a) at $0.3 \mathrm{~g}$

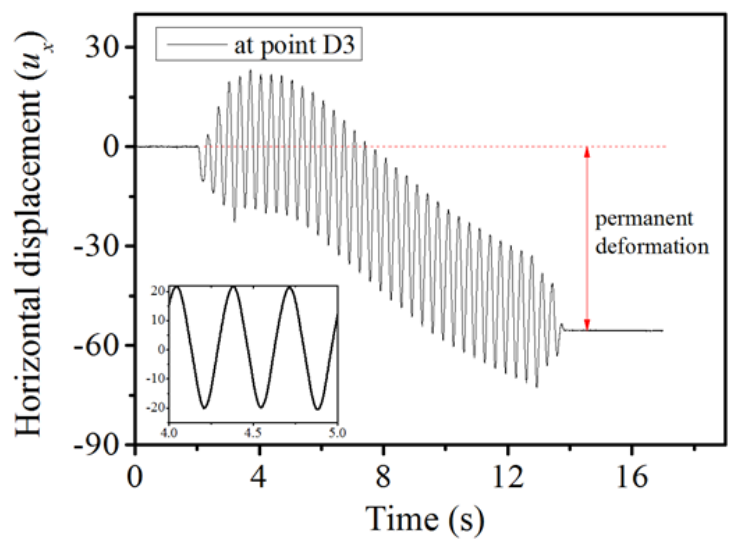

(c) at $0.5 \mathrm{~g}$

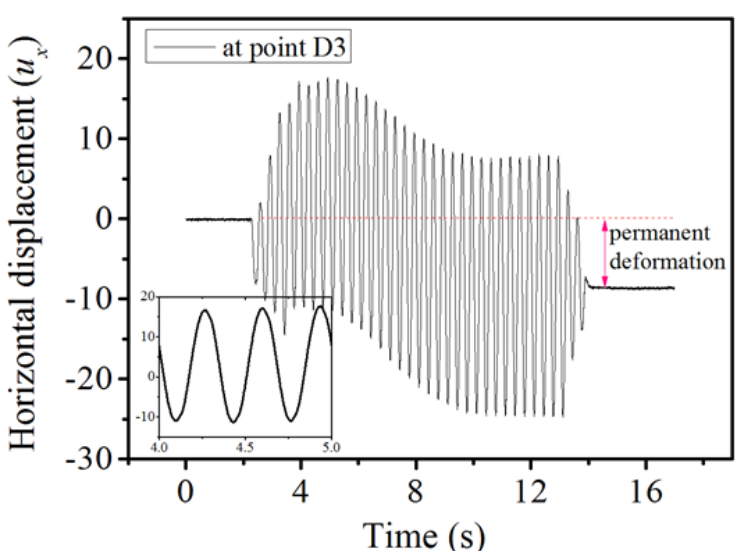

(b) at $0.4 \mathrm{~g}$

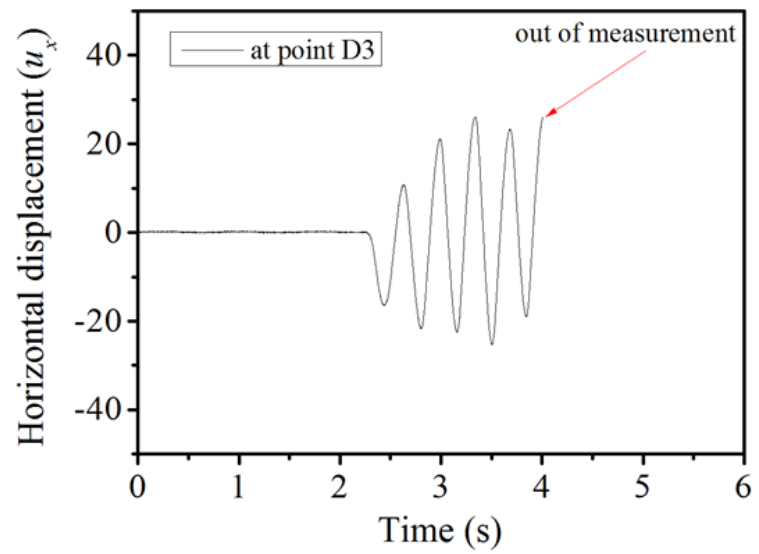

(d) at $0.6 \mathrm{~g}$

Figure 4 Typical time history of the displacement at the surface of slope (displacement unit: $\mathrm{mm}$ ).

obvious deformation. Figure 5 gives the displacement at surface of slope with different values of excitation acceleration. It is observed from the figure that the deformation of slope gradually increases with the increase of excitation amplitude of acceleration. When acceleration is $0.3 \mathrm{~g}$, the horizontal displacements $\left(u_{x}\right)$ at the surface of the slope is already a recognizable value, and the vertical displacement $\left(u_{y}\right)$ at the top of the slope has a value of $11.7 \mathrm{~mm}$. When the acceleration reaches to $0.4 \mathrm{~g}$, the displacement at point of D4 has a larger value of $58 \mathrm{~mm}$, which means the soil at that location has slid away from its original place, and the vertical displacement reaches to $53.7 \mathrm{~mm}$ at $\mathrm{D} 5$. When acceleration is set to $0.5 \mathrm{~g}$, the deformation continues to increase. The displacement at $\mathrm{D} 4$ is outside range of measurement for the case of $0.5 \mathrm{~g}$, and the vertical displacement at D5 is $140 \mathrm{~mm}$, which indicates that there is large settlement at the top of slope. The displacement at $\mathrm{D}_{3}$ is also beyond range of measurement when acceleration is $0.6 \mathrm{~g}$. The D2 and D1 have already larger negative displacements at the acceleration amplitude of $0.6 \mathrm{~g}$, which indicates that the soil at lower part of slope has larger lateral deformation pointing to the outside. It is illustrated from Figure 5 that the deformation at the surface and top of slope continues to develop smoothly when excitation acceleration increases gradually, which is consistent with the failure mode of slope (i.e. creep sliding landslide).

\subsection{Dynamic response of slope}

\subsubsection{Amplification factor of acceleration along elevation of slope}

Figure 6 shows the amplification factor of acceleration along relative elevation. It is shown from the figure that AFA (amplification factor of acceleration) at the surface and inner part of slope has an increasing trend with the increase of relative 


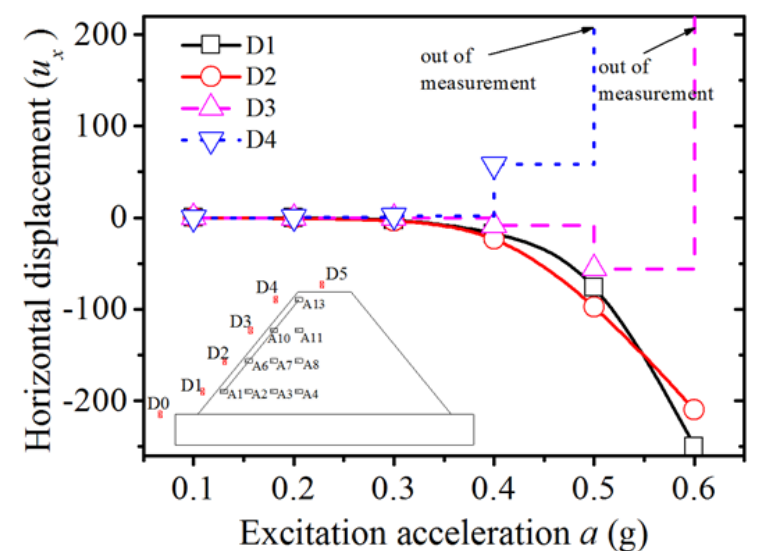

(a) Horizontal displacement at slope surface

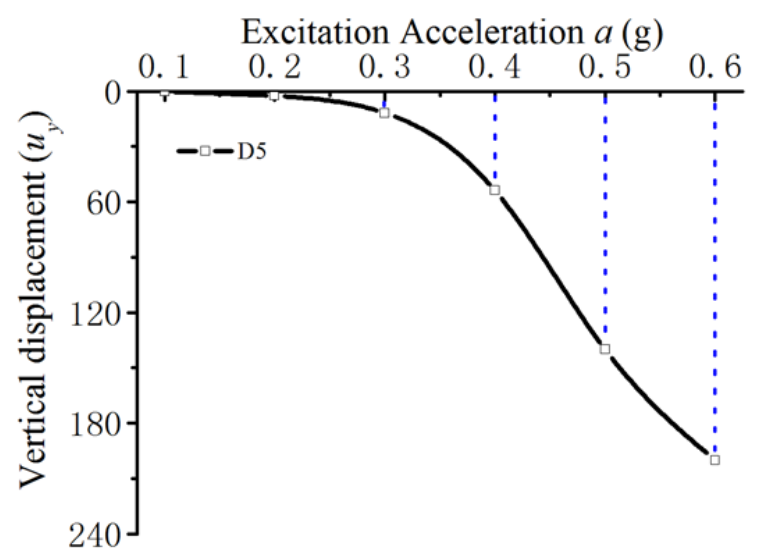

(b) Vertical displacement at top of slope

Figure 5 Variation of displacement at surface of slope with excitation acceleration.

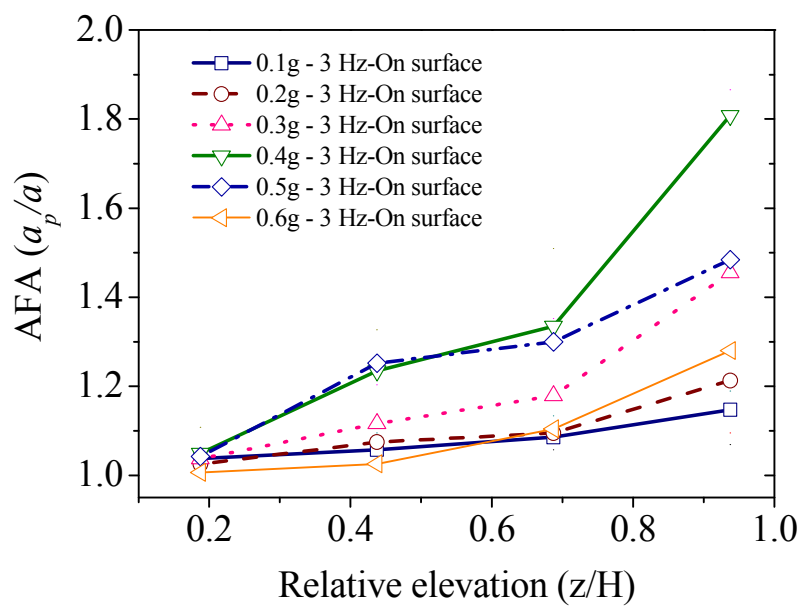

(a) Measuring point at surface of slope (along A1, A6, A10, A13)

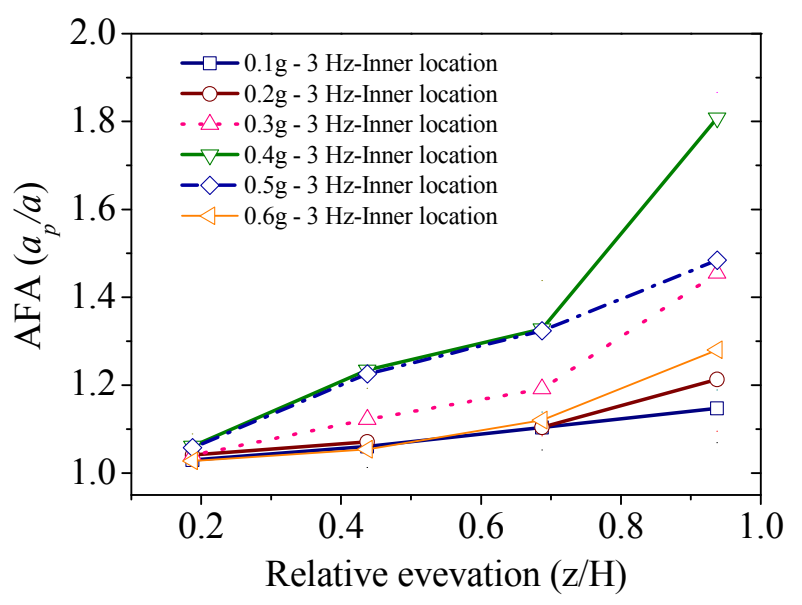

(b) Measuring point at inner slope (along A4, A8, A11, A13)

Figure 6 Variation of amplification factor of acceleration along relative elevation of slope.

elevation $(z / H)$. Near the bottom of slope (e.g. $z / H=0.2$ ), the AFA is smaller than the value of 1.1, which means the amplification effect is slight at the bottom of slope. At the middle of the slope (e.g. $\mathrm{z} / \mathrm{H}=0.4 \sim 0.7)$, there are different amplification effects for different excitation amplitudes. The excitation amplitudes of acceleration (EAA) with the values of $0.4 \mathrm{~g}$ and $0.5 \mathrm{~g}$ induce the largest amplification effect at the middle of slope, and the values of AFA are 1.25 1.29. The EAA with the values of $0.1 \mathrm{~g}-0.3 \mathrm{~g}$ corresponds to the smaller AFA with values of 1.11-1.15. It is observed from the Figure 6a that the AFA at $\mathrm{z} / \mathrm{H}=0.94$ is 1.808 for the case of $0.4 \mathrm{~g}$ at the upper part of slope, which is the largest among the values of AFA induced by $0.1 \mathrm{~g}$ $0.6 \mathrm{~g}$. The amplification effects at surface of slope are similar to those at inner slope, which are illustrated from Figure 6a and Figure 6b.

\subsubsection{Effects of excitation amplitude of acceleration on $A F A$}

Figure 7 shows the variation of amplification factors of acceleration (AFA) at A1, A6, A10 and A13 with excitation amplitude of acceleration (EAA). It can be found from the figure that AFAs at A6, A10 and A13 vary remarkably with increasing EAA, and the AFA at A1 near the bottom of slope varies slightly with the increase of EAA. It is noted that the plastic limit of soil in this test is about 9\% and the liquid limit is about $26 \%$, which means that the soil is at the plastic state. The relationship between AFA and EAA is nonlinear and there is a peak value for AFA between the minimum and the maximum of EAA. Figure 7 shows that the AFA increases nonlinearly with the increase of EAA at point A13 when the EAA is less than $0.4 \mathrm{~g}$ and the 
peak value of AFA occurs at 0.4g. Different from point A13, the AFA at A10 increases with increasing EAA when EAA $<0.436 \mathrm{~g}$ and the peak value of AFA occurs at $0.436 \mathrm{~g}$. At A6 the AFA does so when EAA $<0.466 \mathrm{~g}$ and the peak value appears at 0.466 g. After the peak value, AFA decreases with the increase of EAA. It is indicated that the critical EAA at which the peak value of AFA appears decreases with the increase of elevation on the slope. Based on test data, an empirical formula between AFA $\left(\frac{a_{p}}{a}\right)$, relative elevation $(z / H)$ and dimensionless EAA $(a / g)$ can be summarized as

$$
\begin{gathered}
\frac{a_{p}}{a}=0.94+0.49 \frac{z}{H}+\left(0.35 \frac{z}{H}-0.04\right) \sin \left(4 \pi \frac{a}{g}+\right. \\
\left.0.52 \pi \frac{z}{H}-5.23\right)
\end{gathered}
$$

The computational results at A1, A6, A10 and A13 by the empirical formula (4) are also plotted in Figure 7. It is shown from the figure that computational results agree well with test data, which means that the empirical formula by Eq.(4) is able to describe preferably the relationship between AFA $\left(\frac{a_{p}}{a}\right)$,relative elevation $(z / H)$ and dimensionless EAA $(a / g)$.

According to previous studies (Hardin and Drnevich 1972; Das 1993), the dynamic shear modulus of soil will decrease and damping ratio of soil will increase when the dynamic shear strain increases. From Figures 4 and 5, it is shown that the shear strain varies quickly with the increase of EAA, which indicates that the dynamic shear modulus of soil becomes lower. The soil becomes softer with increasing EAA, and it can be postulated that the damping ratio of soil will also be larger. When the damping ratio and dynamic shear modulus are certain values, the dissipated energy may be larger than input energy. Thus the dynamic response will become weaker and weaker with increasing EAA.

\subsubsection{Effects of frequency parameter on amplification factor of acceleration}

Figure 8 presents the effect of frequency parameter on AFA (amplification factor of acceleration) for the case of excitation amplitude of o.1g. It is observed from the figure that the AFA at the bottom of slope (e.g. at A1) varies slightly with increasing frequency parameter. The AFAs at the middle and upper parts of slope (e.g. at A6, A10, A13) increase distinctly with the increase of frequency parameter. The growth rate of AFA is the largest when frequency parameter changes from 1.14 to 1.42 .

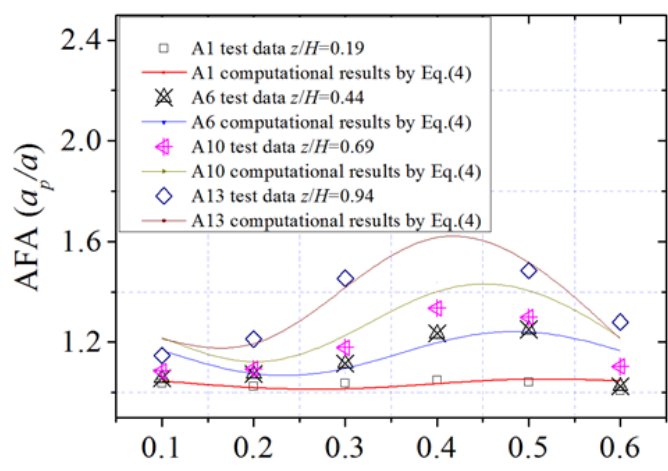

Dimensionless excitation amplitude of acceleration $(\mathrm{a} / \mathrm{g})$

Figure 7 Variation of amplification factor of acceleration (AFA) with excitation amplitude of acceleration (EAA).

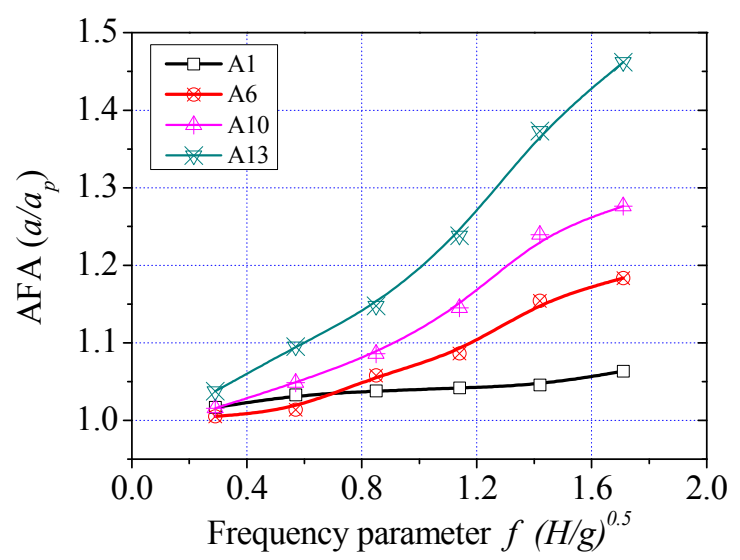

Figure 8 Variation of AFA with frequency parameter $\left(f(H / g)^{0.5}\right.$.

Srilatha et al. (2013) studied three frequencies in their work, i.e. $2 \mathrm{~Hz}, 5 \mathrm{~Hz}, 7 \mathrm{~Hz}$, and also found that the frequency of wave has influences on the acceleration amplification factor. The causes about the effects of frequency can be explained tentatively as follows. The first-order natural frequency of the model slope is about $23 \mathrm{~Hz}$, which can be obtained by analyzing the signal of White noise exerted on the slope. The excitation frequency is gradually close to the first-order natural frequency of the model slope when the frequency parameter increases from 0.29 to 1.71. According to theory of structural dynamics, the maximal vibration amplitude of a structure will appear when excitation frequency is equal to natural frequency of the structure. The vibration amplitude of the structure will be larger when excitation frequency is closer to its natural frequency. Therefore, the model slope will have a larger dynamic response when frequency parameter increases from 0.29 to 1.71 which is gradually close to the natural frequency of model slope. 


\subsection{Comparison with previous studies}

Figure 9a shows the comparison between present studies and the results reported by Liu \& $\mathrm{Xu}$ (2014), Fan et al. (2016), Xu et al. (2008) and Chen et al. (2010), and the detailed test parameters are listed in Table 5. The variation of AFAs with relative elevation reported by present study are consistent with those by Liu \& Xu (2014), Fan et al. (2016), Xu et al. (2008) and Chen et al. (2010), i.e. AFAs increase with the increase of relative elevation. Due to the differences of slope materials, wave types and excitation frequency, the magnitude of AFAs among the results by present study and those by Liu \& Xu (2014), Fan et al. (2016), Xu et al. (2008) and Chen et al. (2010) are different. For instance, the AFAs in the result of Fan et al. (2016) vary slightly along the elevation of slope, which are smaller than those by present study, Liu \& Xu (2014), Xu et al. (2008) and Chen et al. (2010).

Figure $9 \mathrm{~b}$ presents the comparison of AFAs with increasing EFAs between present study and those by Dong et al. (2011), Xu et al. (2008), Yang et al. (2012) and Srilatha et al. (2013), and the detailed test parameters are listed in Table 6. It can be seen from the figure that the results by present study, Xu et al. (2008) and Srilatha et al. (2013) mainly give the results at low EFA (1-6 Hz), and those by Dong et al. (2011) and Yang et al. (2012) mainly present the results at high EFA $(5-20 H z)$. As a whole, EFA at low frequency triggers a lower AFA, and EFA at high frequency induces a higher AFA, as indicated in Figure 10. It is also seen from the figure that the results by present results, $\mathrm{Xu}$ et al. (2008) and Srilatha et al. (2013) and those by Dong et al. (2011) and Yang et al. (2012) are almost harmonious, and both of them give a relatively complete curve about variation of AFA with EFA from $1 \mathrm{~Hz}$ to $2 \mathrm{OHz}$.

\section{Conclusions and Remarks}

A series of shaking table tests were conducted to investigate the failure mode and dynamic response of a double-sided slope with high water content of sandy clay subjected to seismic load. Based on the experimental data, several conclusions are drawn as follows:

1) Different from the most failure mode of

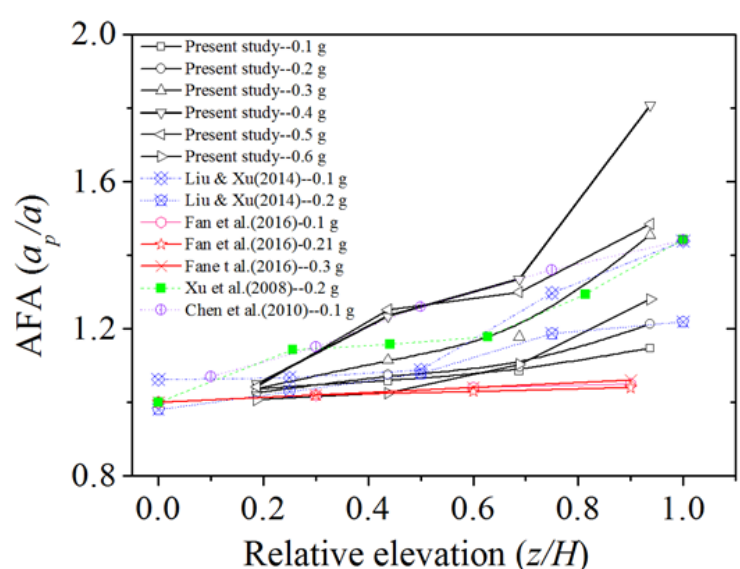

(a)

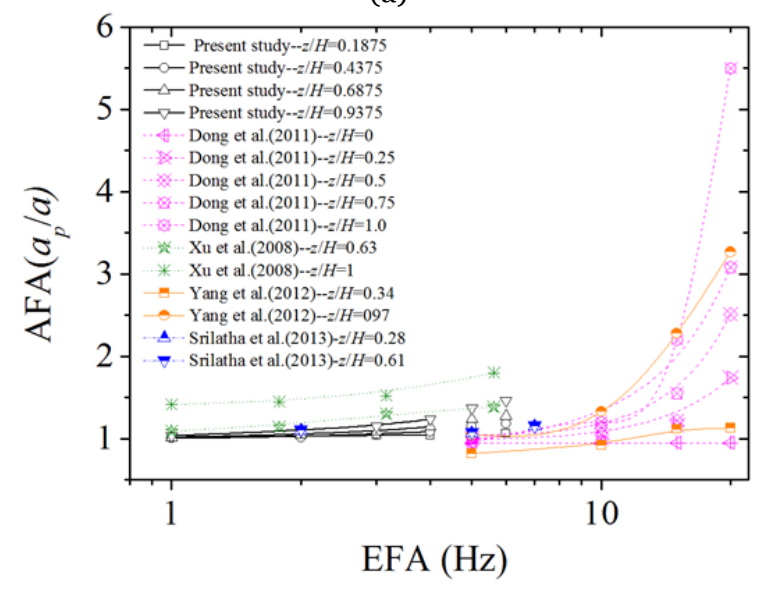

(b)

Figure 9 Variation of Amplification Factor of Acceleration (AFA) with Relative Elevation (a) and Excitation Frequency of Acceleration (EFA) (b).

slope, the failure of a double-sided slope with high water content subjected to seismic load undergoes a process of progressive deformation, and the failure mode can be defined as creep sliding landslide. This type of slope will be in failure at larger excitation acceleration, i.e. more energy is needed to destroy this type of slope, compared with low water content slope.

2) Amplification factor of acceleration (AFA) at the surface and inner part of slope shows an increasing trend with the increase of relative elevation $(\mathrm{z} / \mathrm{H})$. The relation between AFA and excitation amplitude of acceleration (EAA) is nonlinear. An empirical formula that describes preferably the relationship between AFA, relative elevation and dimensionless EAA is given.

3) The amplification factor of acceleration at the middle and upper parts of slope increases distinctly with the increase of excitation frequency of acceleration. 
Table 5 Experimental parameters in Figure 9a

\begin{tabular}{|c|c|c|c|c|c|}
\hline Load & Magnitude & Frequency (Hz) & $\begin{array}{l}\text { Location of } \\
\text { measuring point }\end{array}$ & $\begin{array}{l}\text { Slope } \\
\text { material }\end{array}$ & Source \\
\hline Sine wave & $\begin{array}{l}0.1 \mathrm{~g}, 0.2 \mathrm{~g}, 0.3 \mathrm{~g} \\
0.4 \mathrm{~g}, 0.5 \mathrm{~g}, 0.6 \mathrm{~g}\end{array}$ & 3 & At surface & Sandy clay & Present study \\
\hline Sine wave & $0.1 \mathrm{~g}, 0.2 \mathrm{~g}$ & 10 & At surface & \multirow{2}{*}{$\begin{array}{l}\text { Rock } \\
\text { Rock }\end{array}$} & Liu \& Xu (2014) \\
\hline EL-Centro wave & $0.1 \mathrm{~g}, 0.21 \mathrm{~g}, 0.3 \mathrm{~g}$ & $\begin{array}{l}10.6 \\
\text { (main frequency) }\end{array}$ & At inner slope & & Fan et al. (2016) \\
\hline EL-Centro wave & $0.2 \mathrm{~g}$ & 5.62 & At surface & Gravelly soil & Xu et al. (2008) \\
\hline EL-Centro wave & $0.1 \mathrm{~g}$ & $1.2-3.9$ & At surface & Clay & Chen et al. (2010) \\
\hline
\end{tabular}

Table 6 Experimental parameters in Figure $9 \mathrm{~b}$

\begin{tabular}{l|l|l|l|l|l|} 
Load & Magnitude & Frequency $(\mathrm{Hz})$ & $\begin{array}{l}\text { Location of } \\
\text { measuring point }\end{array}$ & Slope material & Source \\
\hline Sine wave & $0.1 \mathrm{~g}$ & $1,2,3,4,5,6$ & At surface & Sandy clay & Present study \\
\hline Sine wave & $0.1 \mathrm{~g}$ & $5,10,15,20$ & At surface & Rock & Dong et al. (2011) \\
Sine wave & $0.1 \mathrm{~g}$ & $5,10,15,20$ & At surface & Rock & Yang et al. (2012) \\
EL-Centro wave & $0.1 \mathrm{~g}$ & $1,1.77,3.16,5.62$ & At surface & Gravelly soil & Xu et al. (2008) \\
Sine wave & $0.3 \mathrm{~g}$ & $\mathbf{2 , 5}, 7$ & At inner slope & Clayey sand & Srilatha et al. (2013) \\
\hline
\end{tabular}

\section{Acknowledgments}

This study was supported by National Natural Science Foundation of China (Grant No. 10902112), the Fundamental Research Funds for the Central
Universities (2682017QYo2) and the National Key R\&D Program of China (2016YFCo802203), and the Youth Innovation Promotion Association CAS.

\section{References}

Arango I, and Seed HB(1974) Seismic stability and deformation of clay slopes. Journal of Geotechnical Engineering Division, ASCE 100(2): 139-156.

Chen XM, Shen J, Wei P, et al. (2010) Large-scale shaking table test of seismic stability of Xiashu Loess slope: analysis of test results. Journal of Disaster Prevention and Mitigation Engineering 30(6): 587-594. (In Chinese)

Cruden DM, Varnes DJ (1996) Landslide types and processes. In: Turner AK, Schuster RL (eds.) Landslides investigation and mitigation. Transportation Research Board, US National Research Council. Special Report 247, Washington, DC, Chapter 3, pp. 36-75.

Dong JY, Yang GX, Wu FQ, Qi SW(2011) The large-scale shaking table test study of dynamic response and failure mode of bedding rock slope under earthquake. Rock and Soil Mechanics 32(10): 2977-2982. (In Chinese) Fan G, Zhang JJ, $\mathrm{Wu} \mathrm{JB}$, et al. (2016) Dynamic response and dynamic failure mode of a weak intercalated rock slope using a shaking table. Rock mechanics and rock engineering 49(8): 1-14. https://doi.org/10.1007/s00603-016-0971-7

Hardin BO, Drnevich VP (1972) Shear modulus and damping in soils: Design equations and curves. Journal of the soil mechanics and foundation division( ASCE) 98(sm7): 667-692.

Huang RQ, Li WL (2009a) Development and distribution of geohazards triggered by the 5.12 WenchuanEarthquake in China. Science China Series E (Technology Science) 52: 810819. https://doi.org/10.1007/s11431-009-0117-1

Huang RQ, Li WL (2009b) Analysis of the geo-hazards triggered by the 12 May 2008 Wenchuan Earthquake, China. Bulletin of Engineering Geology and the Environment 68: 363-371. https://doi.org/10.1007/s10064-009-0207-o
Huang RQ, Xu Q, Huo JJ (2011) Mechanism and Geomechanics models of landslides triggered by 5.12 Wenchuan Earthquake. Journal of Mountain Science 8: 200-210. https://doi.org/10.1007/s11629-011-2104-9

Huang RQ, Pei XJ, Fan XM, et al. (2012) The characteristics and failure mechanism of the largest landslide triggered by the Wenchuan earthquake, May 12, 2008, China. Landslides 9: 131-142. https://doi.org/10.1007/s10346-011-0276-6

Hungr O, Leroueil S, Picarelli L (2014) The Varnes classification of landslide types, an update. Landslides 11: 167-194. https:// doi.org/10.1007/s10346-013-0436-y

Latha GM, Garaga A (2010). Seismic stability analysis of a Himalayan rock slope. Rock Mechanics and Rock Engineering 43:831-843. https://doi.org/10.1007/s00603-010-0088-3

Lin ML, Wang KL (2006) Seismic slope behavior in a large-scale shaking table model test. Engineering Geology 86(2): 118133.https://doi.org/10.1016/j.enggeo.2006.02.011

Ling HI, MohriY, Leshchinsky D, et al. (2005) Large-scale shaking table tests on modular-block reinforced soil retaining walls. Journal of Geotechnical and Geoenvironmental engineering 131: 465-476. https://doi.org/10.1016/(ASCE) 1090-0241(2005)131:4(465)

Liu HX, Xu Q, Li YR, et al. (2013). Response of high-strength rock slope to seismic waves in a shaking table test. Bulletin of the Seismological Society of America 103: 3012-3025. https:// doi.org/10.1785/0120130055

Liu HX, Xu Q, Li YR (2014). Effect of lithology and structure on seismic response of steep slope in a shaking table test. Journal of Mountain Science 11(2): 371-383. https://doi.org/10.1007/ s11629-013-2790-6

Srilatha N, MadhaviLatha G, Puttappa CG (2013) Effect of 
frequency on seismic response of reinforced soil slopes in shaking table test. Geotextiles and Geomembranes 36: 27-32. https://doi.org/10.1016/j.geotexmem.2012.10.004

Taylor DW (1937) Stability of earth slopes. Journal of the Boston Society of Civil Engineers 24: 197-246.

Varnes DJ (1954) Landslide types and processes. In: Eckel EB (ed.) Landslides and engineering practice, special report 28. Highway Research Board, National Academy of Sciences, Washington, DC. pp 20-47.

Varnes DJ (1978) Slope movement types and processes. In: Schuster RL, Krizek RJ (eds.) Landslides, analysis and control, special report 176: Transportation Research Board, National Academy of Sciences, Washington, DC. pp 11-33.

Vanapalli SK, Fredlund DG, Pufahl DE, et al. (1996) Model for the prediction of shear strength with respect to soil suction. Canadian Geotechnical Journal 33: 379-392. https://doi.org/ 10.1139/t96-060

Wasowski J, Keefer DK, Lee CT (2011) Toward the next generation of research on earthquake-induced landslides: current issues and future challenges. Engineering Geology 122: 1-8. https://doi.org/10.1016/j.enggeo.2011.06.001

Wang KL, Lin ML (2011) Initiation and displacement of landslide induced by earthquake- a study of shaking table model slope test. Engineering Geology 122: 106-114. https://doi.org/ 10.1016/j.enggeo.2011.04.008

Xie W, Zhang DW, Yang S (2017) Impact of moisture content on variation of small-strain shear modulus of compacted subgrade soil. Rock and Soil Mechanics 38(5): 1273-1280. (in Chinese)

Xu GX, Yao LK, Gao ZN, et al. (2008) Large-scale shaking table model test study on dynamic characteristics and dynamic responses of slope. Chinese Journal of Rock Mechanics and Engineering 27(3): 624-632. (In Chinese)

Yang J, Sato T, Savidis S, et al. (2002). Horizontal and vertical components of earthquake ground motions at liquefiable sites. Soil Dynamics and Earthquake Engineering 22: 229-240. https://doi.org/10.1016/s0267-7261(02)00010-6

Yang GX, Wu FQ, Dong JY, et al. (2012) Study of dynamic response characters and failure mechanism of rock slope under earthquake. Chinese Journal of Rock Mechanics and Engineering 31(4): 696-702. (In Chinese)

Das Braja M (1993) Principles of soil dynamics. Boston: PWSKent Publishing Company.

Zhao SP, Zhu YL, He P, et al. (2003) Testing study on dynamic mechanics parameters of frozen soil. Chinese Journal of Rock Mechanics and Engineering 22(suppl2): 2677-2681. (In Chinese)

Zhang XD, Liu JS, Lan CY, et al. (2011) Dynamic test analysis of frozen Aeolian soil under earthquake loading. The Chinese Journal of Geological Hazard and Control 22(2): 135-142. (In Chinese) 